\title{
Low Frequency Internal Friction Study on Vanadium-Deuterium Alloys
}

\author{
By Osamu Yoshinari*, Masahiro Koiwa**, \\ Hajime Asano** and Makoto Hirabayashi**
}

\begin{abstract}
Low frequency internal friction measurements have been performed on vanadium-deuterium alloys over a temperature range from -190 to $300^{\circ} \mathrm{C}$. The terminal solubility of deuterium in vanadium is found to increase by the addition of a small amount of oxygen. The binding energy of deuterium to oxygen has been estimated to be about $0.10 \mathrm{eV}$.

It has been found that, besides the main precipitation peak, a small peak gradually develops at a lower temperature with the repetition of measurements or thermal cyclings. Since torsional deformation also introduces a peak at the same temperature, the peak is identified as due to dislocations punched out from deuteride precipitates. The main precipitation peak is found to consist of two components: the transient and the equilibrium components. The transient component increases with the increase in the cooling or heating rate, and is inversely proportional to measuring frequencies. The transient internal friction is believed to be associated with the formation or dissolution of hydride precipitates as proposed by Köster and his coworkers for a damping peak in Ti-H alloys.
\end{abstract}

(Received December 2, 1977)

\section{Introduction}

The behaviour of hydrogen (deuterium) in vanadium, niobium and tantalum has been studied extensively by internal friction measurements, as recently reviewed by Schiller ${ }^{(1)}$. On cooling specimens containing hydrogen, an abrupt increase in internal friction is observed. This internal friction is called the precipitation peak and is believed to be associated with the beginning of the hydride precipitation; the phenomenon has been utilized to determine the solubility of hydrogen. With this technique, Chang and Wert $^{(2)}$ have shown that the solubility of hydrogen in vanadium is considerably affected by impurity interstitials such as oxygen, nitrogen and carbon.

Although it is generally agreed that the damping peak is closely associated with the precipitation, the detailed mechanism of the peak is still a subject of arguments. Proposed mechanisms may be classified into two groups:

(1) Due to the large difference in specific volumes of metals and hydride precipitates

* Graduate School, Tohoku University, Sendai 980, Japan.

** The Research Institute for Iron, Steel and Other Metals, Tohoku University, Sendai 980, Japan. (e.g. about $6 \%$ for $\mathrm{V}-\mathrm{H}$ and $\mathrm{V}-\mathrm{D}$ ), dislocations are generated around precipitates. The motion of such dislocations with or without hydrogen atmosphere is considered to be the origin of the precipitation peak ${ }^{(3) \sim(6)}$.

(2) Precipitates themselves may be the cause of the peak ${ }^{(5)(7) \sim(10)}$. For example, short range or long range diffusion of hydrogen in hydrides might give rise to the relaxation effect.

Although the dislocation models seem to be most popular, it is felt that further experimental studies are required before we arrive at a more complete understanding of the phenomenon.

The aim of the present paper is twofold; (1) to investigate the effect of impurity oxygen on the solubility of deuterium in vanadium and (2) to study the nature of the precipitation peak in detail.

\section{Experimental}

\section{Specimen preparation}

Vanadium used in this investigation was supplied from Nihon Gaishi Inc. in the form of granules $(99.8 \%$ purity). The result of chemical analysis of the raw material is given in Table 1. From the ingot prepared by electron beam melting, wires of $0.6 \mathrm{~mm}$ in diameter were 
Table 1 Chemical analysis of vanadium granules (in weight ppm).

\begin{tabular}{llllllllll}
\hline Al & $\mathrm{Fe}$ & $\mathrm{Si}$ & $\mathrm{Cr}$ & $\mathrm{C}$ & $\mathrm{Ni}$ & $\mathrm{Cu}$ & $\mathrm{H}$ & $\mathrm{O}$ & $\mathrm{N}$ \\
\hline 560 & 900 & 28 & 25 & 86 & $\mathrm{Tr}$ & 70 & 45 & 230 & 36 \\
\hline
\end{tabular}

made by swaging and cold drawing without intermediate annealing. Some measurements were made on specimens taken from the asdrawn wire which will be labelled as $\mathrm{V}-\mathrm{CW}$. In order to examine the effect of oxygen, two kinds of specimens with different contents of oxygen were prepared from $\mathrm{V}-\mathrm{CW}$ in the following way. To reduce the oxygen content, wires $(\mathrm{V}-\mathrm{CW})$ were wrapped with zirconium foils ( $20 \mu \mathrm{m}$ thickness), sealed in an evacuated quartz tube and annealed for $2 \mathrm{~h}$ at $1070^{\circ} \mathrm{C}$. This procedure utilizes the higher affinity of zirconium to oxygen than that of vanadium and was first proposed by Abe, Toma, Yoshinaga and Morozumi ${ }^{(11)}$ to obtain vanadium specimens with low oxygen content. The specimens thus prepared will be referred to as $\mathrm{V}-\mathrm{ZA}$ (annealed in zirconium foil). Wires (V-CW) annealed similarly but without zirconium foils will be labelled as $\mathrm{V}-\mathrm{A}$; the oxygen content of latter specimens increases by absorbing oxygen due to the decomposition of quartz $\left(\mathrm{SiO}_{2}\right)$. The oxygen contents of specimens $\mathrm{V}-\mathrm{CW}$, V-ZA and V-A were evaluated from the Snoek peak height (see Fig. 1), and numerical values are given in Table 2 together with the residual resistivity ratio.

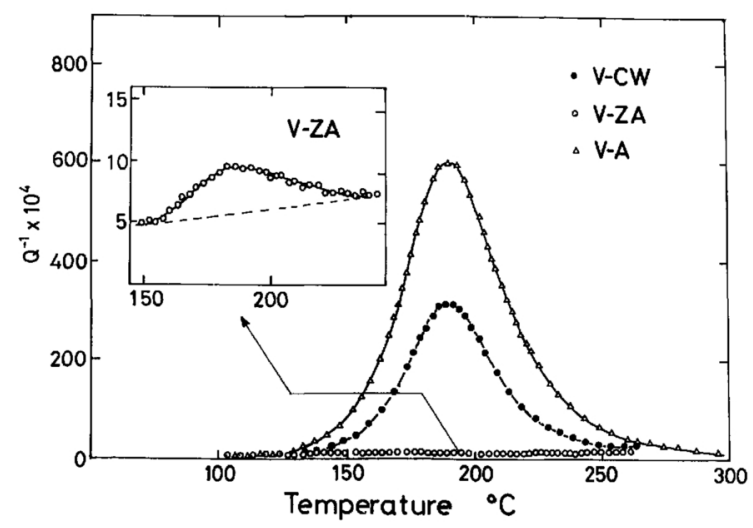

Fig. 1 Snoek peaks of $\mathrm{V}-\mathrm{CW}, \mathrm{V}-\mathrm{A}$ and $\mathrm{V}-\mathrm{ZA}$ specimens.
Table 2 Snoek peak heights and residual resistivity ratios.

\begin{tabular}{lrrr}
\hline & $Q_{\max }^{-1}$ & \multicolumn{1}{c}{ O/V* } & RRR** \\
\hline V-CW & $300 \times 10^{-4}$ & $3800 \times 10^{-6}$ & 10.9 \\
V-ZA & $3 \times 10^{-4}$ & $38 \times 10^{-6}$ & 186.9 \\
V-A & $600 \times 10^{-4}$ & $7500 \times 10^{-6}$ & 5.99 \\
\hline
\end{tabular}

* The proportionality constant relating the Snoek peak height and the oxygen content was taken from the work by Hörtz ${ }^{(12)}$.

** The ratio of the resistivity measured at room temperature and at $4.2 \mathrm{~K}$.

Table 3 Summary of results for V-D specimens.

\begin{tabular}{lccccc}
\hline & $\mathrm{D} / \mathrm{V}$ & $\mathrm{O} / \mathrm{V} \times 10^{6}$ & $T_{C}$ & $\Delta T_{C H}$ & $N_{T}$ \\
\hline $\mathrm{V}-1 \mathrm{D}$ & 0.017 & 390 & $-4{ }^{\circ} \mathrm{C}$ & $5^{\circ} \mathrm{C}$ & - \\
$\mathrm{V}-$ 2D & 0.033 & 380 & 12 & 8 & - \\
$\mathrm{V}-6 \mathrm{D}$ & 0.069 & 190 & 50 & 2 & - \\
$\mathrm{V}-12 \mathrm{D}$ & 0.113 & 130 & 71 & 4 & - \\
\hline $\mathrm{V}-1 \mathrm{D}-\mathrm{O}$ & 0.017 & 7700 & $-32^{\circ} \mathrm{C}$ & $4^{\circ} \mathrm{C}$ & 1.4 \\
$\mathrm{~V}-$ 2D-O & 0.028 & 6800 & -16 & 7 & 2.5 \\
$\mathrm{~V}-6 \mathrm{D}-\mathrm{O}$ & 0.074 & 7600 & 36 & 21 & 2.9 \\
$\mathrm{~V}-12 \mathrm{D}-\mathrm{O}$ & 0.112 & 9700 & 46 & 34 & 4.7 \\
\hline \hline
\end{tabular}

Deuterium was introduced into $\mathrm{V}-\mathrm{ZA}$ and V-A specimens by equilibrating with an appropriate amount of vanadium deuteride powder $\left(\mathrm{VD}_{0.16}\right)$ in a glass tube for one week at $500^{\circ} \mathrm{C}$. The deuterized specimens are labelled as $\mathrm{V}-\mathrm{D}$ and $\mathrm{V}-\mathrm{D}-\mathrm{O}$. The concentration of deuterium of each specimen is determined by gas extraction technique.

The contents of deuterium and oxygen in $\mathrm{V}-\mathrm{D}$ and $\mathrm{V}-\mathrm{D}-\mathrm{O}$ series specimens are shown in Table 3 together with some experimental results to be explained in due course. Note that, in Table 3, the number in the specimen names indicates the nominal content of deuterium in atomic percent. It is added here that the oxygen concentrations of $\mathrm{V}-\mathrm{D}$ specimens are higher than that of V-ZA $(\sim 40$ at.ppm); this is probably due to contamination during the deuterization process.

\section{The internal friction measurement}

The internal friction was measured in an inverted torsion pendulum over a temperature range from -190 to $+300^{\circ} \mathrm{C}$. The details of the apparatus were described elsewhere ${ }^{(13)}$; 
some modifications were made to allow an automatic recording of the values of the internal friction, the period of vibrations and the temperature. The measuring frequency can be changed from 0.5 to $5 \mathrm{~Hz}$. The strain amplitude in the maximum surface shear strain is typically about $10^{-5}$. The cooling and heating rates were changed from 0.25 to $2.5^{\circ} \mathrm{C} / \mathrm{min}$.

\section{Experimental Results}

\section{Solubility of deuterium}

Figure 2 shows the internal friction of a V-1D specimen which contains 1.7 at \% deuterium. On cooling and subsequent heating runs, a characteristic damping peak, the so-called precipitation peak, is observed during the precipitation or the dissolution of deuterides. At lower temperatures curves for the cooling and the heating runs coincide, while a thermal hysteresis $\left(\sim 10^{\circ} \mathrm{C}\right)$ is observed at higher temperatures. For cooling runs, the rise of the internal friction is abrupt enough to define the precipitation temperature for cooling, $T_{C}$, while for heating runs the decrease of the internal friction to the background value is gradual so that it is difficult to define a unique temperature, $T_{H}$, the dissolution temperature for heating. To define the magnitude of the thermal hysteresis $\Delta T_{C H}$, we will conveniently take the difference between the temperatures of half maximum of the internal friction peaks for cooling and heating runs.

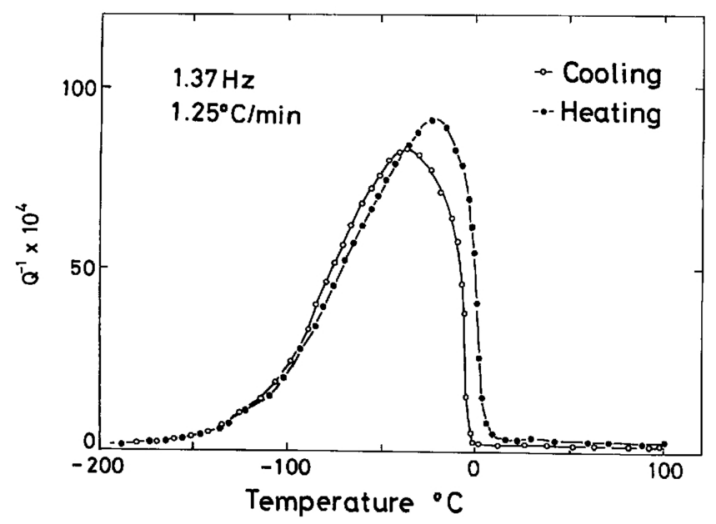

Fig. 2 Internal friction curves of $\mathrm{V}-1 \mathrm{D}$ specimen on cooling and heating runs.

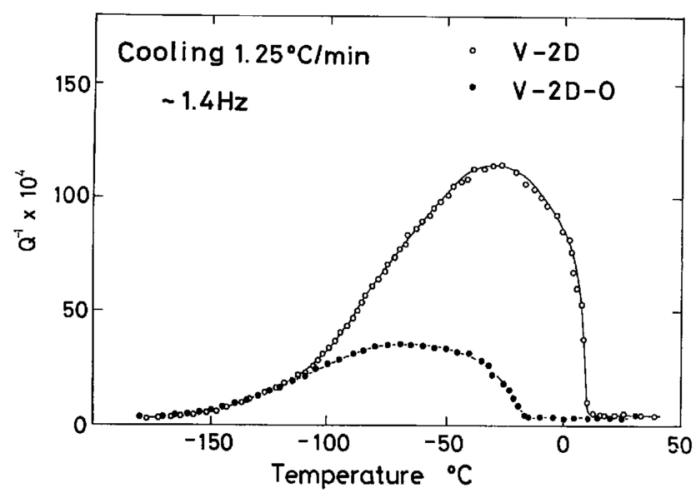

Fig. 3 The precipitation peaks of $V-2 D$ and $V-2 D-O$ specimens.

Figure 3 compares the cooling curves for $\mathrm{V}$ $2 \mathrm{D}$ and $\mathrm{V}-2 \mathrm{D}-\mathrm{O}$ specimens. Oxygen lowers the temperature of precipitation $T_{C}$ by about $30^{\circ} \mathrm{C}$, and reduces the peak height to about onefourth. Similar measurements of the internal frictions were made for various specimens, and the curves for cooling runs for V-D and V-D-O series specimens are shown in Fig. 4(a) and (b), respectively. With the increase in the deuterium concentration, the peak height increases and $T_{C}$ shifts towards higher temperatures. It is to be noted here that the zero point drift or the twisting of wire specimens occurs actively with the formation of precipitates. This effect was observed on $\mathrm{V}-\mathrm{H}$ specimens by Owen and Scott ${ }^{(14)}$ who called the phenomenon the "Poynting effect". The effect is larger for specimens with higher deuterium contents. In fact, for the V-12D specimen in Fig. 4(a), the measurement became impossible at lower temperatures because of too large twisting.

The values of $T_{C}$ determined from the curves in Fig. 4 are plotted as a function of composition $\mathrm{D} / \mathrm{V}$ in Fig. 5. The addition of oxygen shifts the solubility limit to higher deuterium concentration, or lowers the temperature of precipitation. From the gradients of the lines, the apparent heat of solution $H_{S}$ is determined to be $0.20 \mathrm{eV}$ and $0.16 \mathrm{eV}$ for V-D and V-D-O alloys, respectively. The thermal hysteresis, $\Delta T_{C H}$, for the two series of specimens are plotted in Fig. 6 as a function of deuterium concentration; for $\mathrm{V}-\mathrm{D}$ specimens $\Delta T_{C H}$ is virtually independent of the deuterium contents, while that 


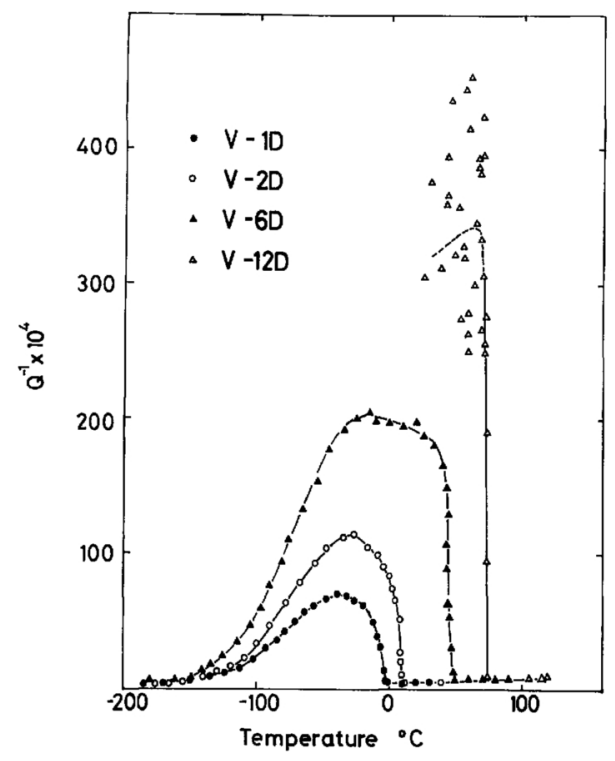

(a)

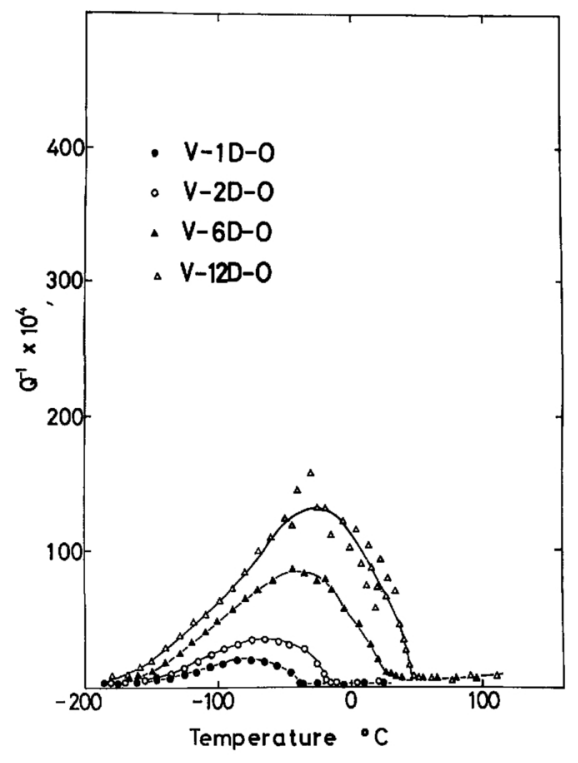

(b)

Fig. 4 The precipitation peaks of V-D and V-D-O specimens on cooling run.

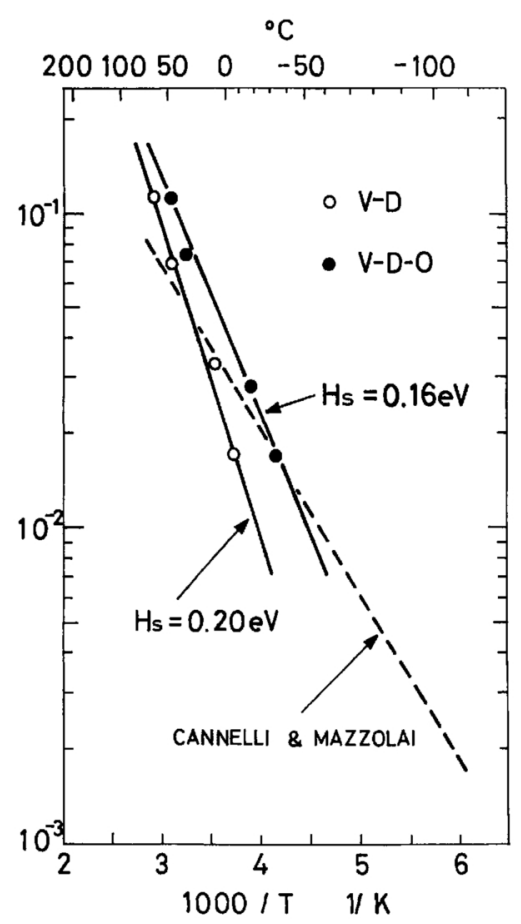

Fig. 5 The solubility of deuterium as a function of reciprocal temperature.

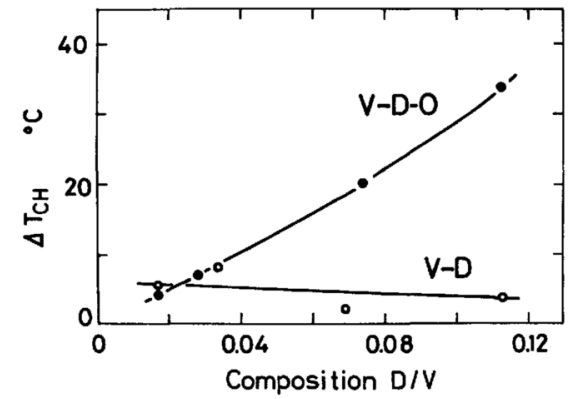

Fig. 6 The thermal hysteresis of V-D and V-D-O specimens as a function of deuterium concentration.

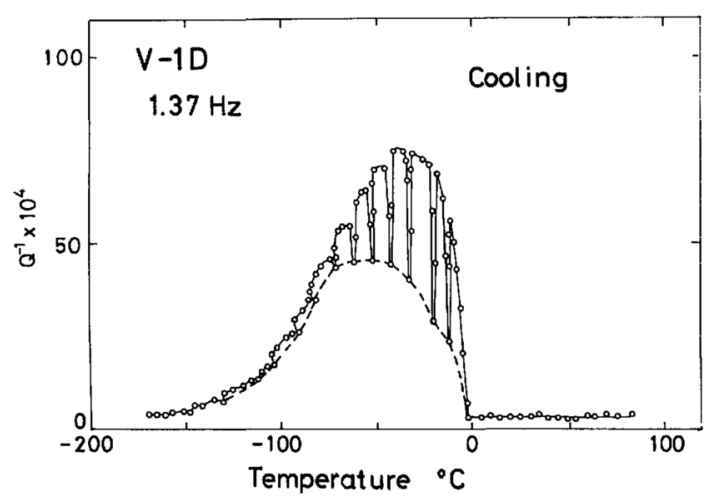

Fig. 7 The effect of temperature holding on the precipitation peak. 
of $\mathrm{V}-\mathrm{D}-\mathrm{O}$ specimens is larger for higher concentrations.

\section{The behavior of the precipitation peak}

In order to study in detail the characteristics of the precipitation peak, various types of measurements were performed on one specimen V-1D as described below. The internal friction versus temperature curves shown so far were taken at a constant heating or cooling rate. Figure 7 shows the effect of temperature holding on the way of cooling at a rate of $1.25^{\circ} \mathrm{C} /$ min; when cooling is stopped temporarily so as to keep the specimen at certain constant

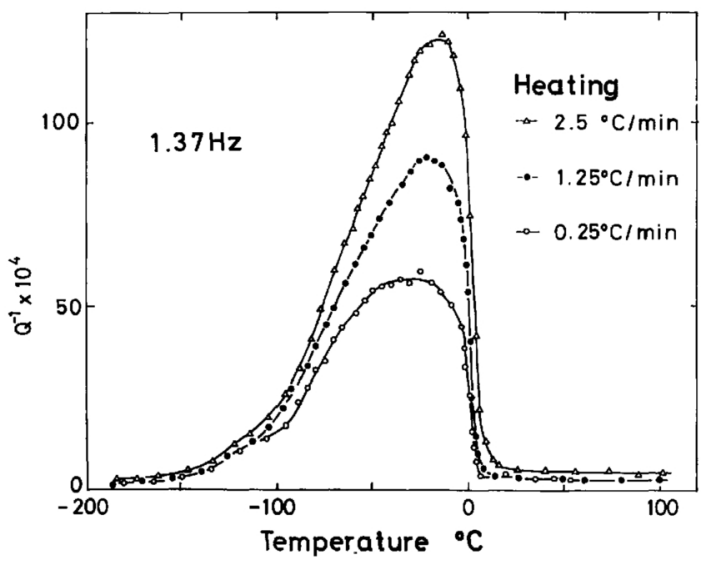

Fig. 8 The precipitation peaks at different heating rates.

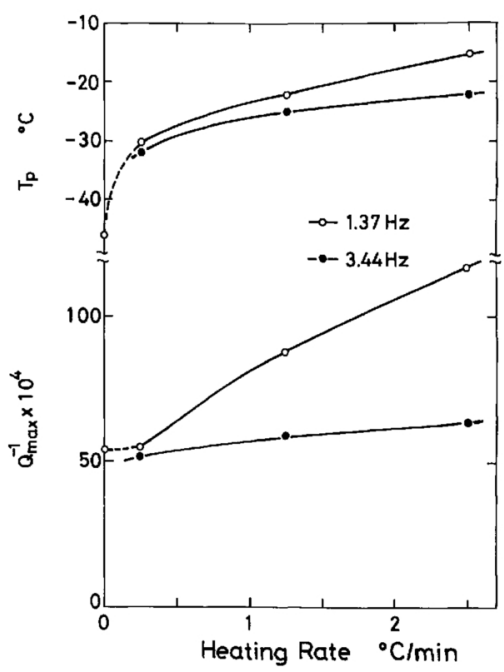

Fig. 9 The variation of peak heights and peak temperatures with the heating rate. temperatures, the internal friction decreases and approaches some equilibrium value within about $15 \mathrm{~min}$. When one starts to cool the specimen again, the internal friction recovers some stationary value corresponding to the cooling rate. The above observation indicates that the peak has two components; a transient component which depends on the heating or cooling rate, and an equilibrium component (dotted line in Fig. 7). Figure 8 shows the precipitation peaks at different heating rates;

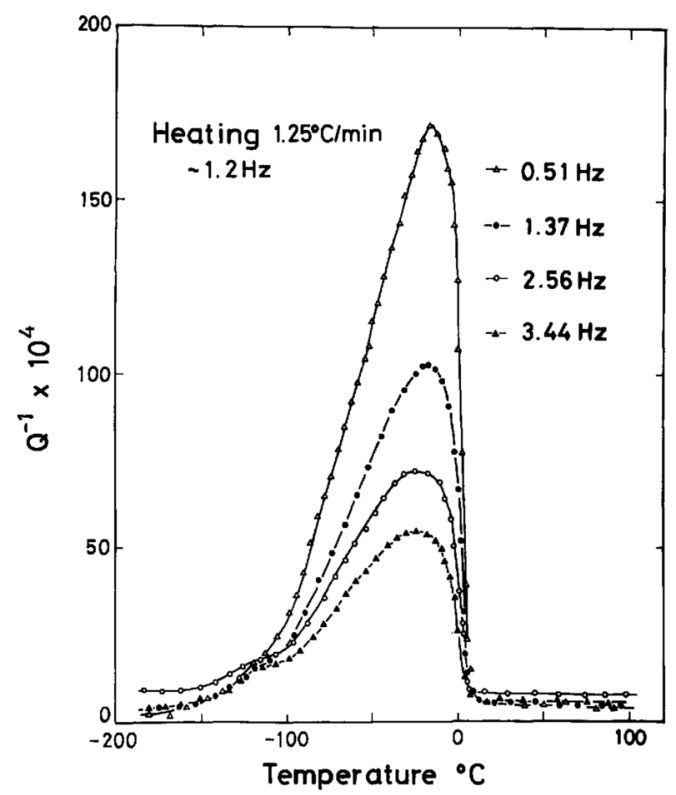

Fig. 10 The precipitation peaks at different frequencies.

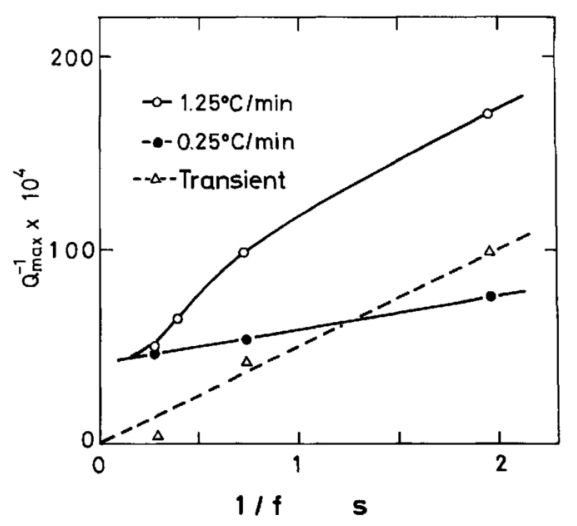

Fig. 11 The peak heights versus reciprocals of the frequency. Transient component is the difference in the values for 1.25 and $0.25^{\circ} \mathrm{C} / \mathrm{min}$. 
$0.25,1.25$ and $2.5^{\circ} \mathrm{C} / \mathrm{min}$, and Fig. 9 summarizes the peak height $Q_{\max }^{-1}$ and peak temperature $T_{p}$; the points for zero heating rate were taken from the temperature holding experiment shown in Fig. 7. Note that the peak height depends on heating rate linearly and that there exists a considerable magnitude of internal friction at the zero heating rate, which is referred to as the equilibrium component in the above.

The frequency dependence of the precipitation peak was also examined and the result for a heating rate of $1.25^{\circ} \mathrm{C} / \mathrm{min}$ is shown in Fig. 10. The peak height is plotted in Fig. 11 as a function of reciprocal frequencies; the result for a slower heating rate of $0.25^{\circ} \mathrm{C} / \mathrm{min}$ is also shown in the figure. Since the internal friction measured at the rate of $0.25^{\circ} \mathrm{C} / \mathrm{min}$ is approximately the same as that of equilibrium as shown in Fig. 9, the difference between the internal frictions for the two heating rates can be regarded as the transient component. Note that both the transient and the equilibrium components show almost linear dependence on the reciprocals of measuring frequencies.

In the course of repeated measurements over a temperature range from -190 to $100^{\circ} \mathrm{C}$, it was noticed that a shoulder or a small peak gradually develops at $-120^{\circ} \mathrm{C}$; Figure $12 \mathrm{com}$ pares the internal frictions for the first and 28 th heating runs. This small peak disappears after in-situ heating up to $300^{\circ} \mathrm{C}$. After this annealing, the specimen was subjected to a torsional deformation of $3 \%$ (in the surface shear strain) in order to examine a possible relationship of the peak to dislocations. As shown in Fig. 13, a well developed peak is observed at the same temperature. After heating up to $300^{\circ} \mathrm{C}$, the peak disappeared again.

\section{Discussion}

\section{Binding energy of deuterium to oxygen}

As shown in Fig. 5, the solubility of deuterium in vanadium increases by the addition of oxygen, which is interpreted as the trapping effect. By comparing the solubility in the two types of specimens, $C_{D}$ and $C_{D O}$ at the same temperature, the average number of trapped deuterium

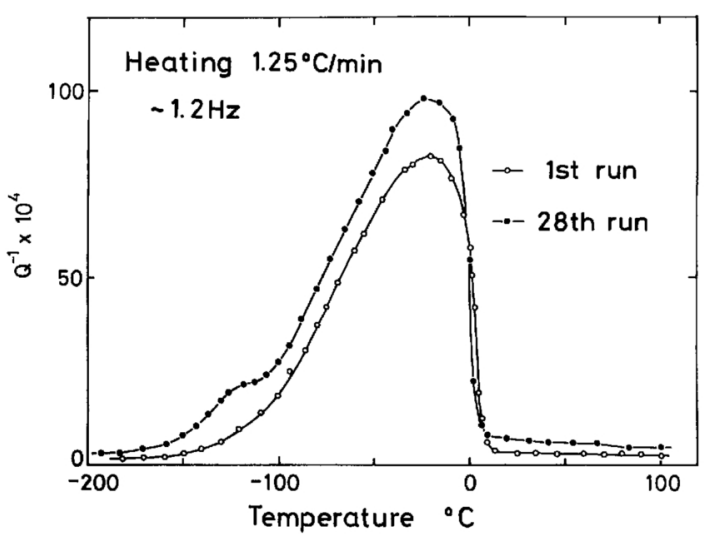

Fig. 12 The precipitation peaks at the 1st and 28th heating runs.

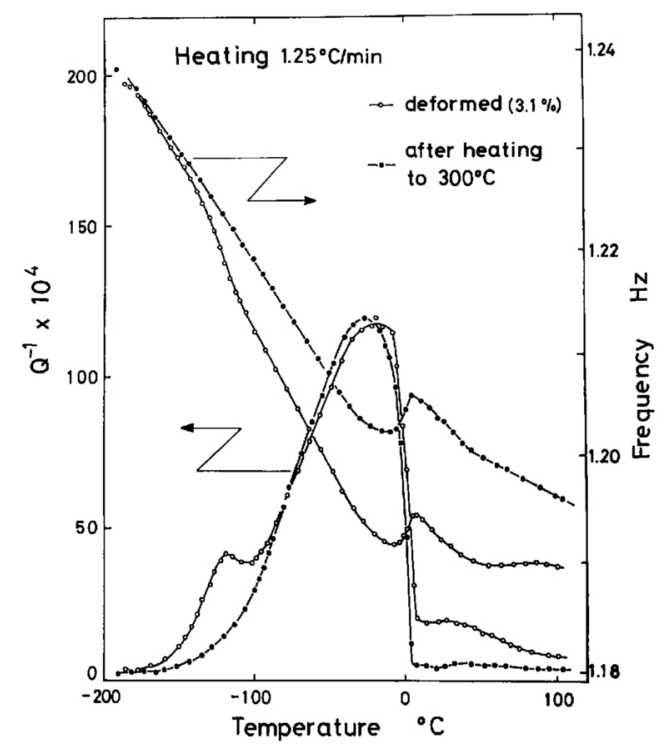

Fig. 13 The internal frictions and the vibrational frequencies after deformation, and after subsequent annealing up to $300^{\circ} \mathrm{C}$.

atoms to one oxygen atom can be calculated as

$$
N_{T}=\frac{C_{D O}-C_{D}}{C_{O}}
$$

where $C_{O}$ is the oxygen content. The value of $N_{T}$ is shown in Table 3.

The solubility of deuterium in V-D and $\mathrm{V}-\mathrm{D}-\mathrm{O}$ alloys may be expressed as

$$
C_{D}=A \exp \left(-H_{S} / k T\right)
$$

where $A$ and $H_{S}$ are 102 and $0.20 \mathrm{eV}$, respectively (see Fig. 5), and 


$$
C_{D O}=C_{D}\left[1-\frac{z C_{O}}{\beta}+\frac{z C_{O}}{z^{\prime} C_{D}+\beta\left(1-\frac{z C_{O}}{\beta}\right) \exp \left(-\frac{E_{B}}{k T}\right)}\right]
$$

where

$z$ : the number of trapping sites per oxygen atom.

$z^{\prime}:$ the number of trapping sites blocked by one trapped deuterium atom.

$\beta$ : the ratio of the number of interstices to that of metal atom sites.

The above equation is originally used by Pfeiffer and Wipf ${ }^{(15)}$. The binding energy $E_{B}$ and the number of trapping sites per oxygen atom have been evaluated for various $z^{\prime}$ as described below $\dagger$. We will use $\beta=6$, which corresponds to the tetrahedral occupancy.

(1) $z^{\prime}=0$

If we neglect the factor, $z C_{o} / \beta$, which expresses the reduction of the number of ordinary sites through the occupation by oxygen atoms, eq. (3) reduces to a simple form,

$$
C_{D O}=C_{D}\left[1+\frac{z C_{O}}{\beta} \exp \left(\frac{E_{B}}{k T}\right)\right],
$$

which is essentially the same as that used by Chang and $\mathrm{Wert}^{(2)}$ for the analysis of the binding energy of $\mathrm{H}$ to $\mathrm{O}$ in vanadium. With this formula, we obtained

$$
E_{B}=0.10 \mathrm{eV}, \quad z=12 .
$$

Note that " $z$ ' $=0$ " implies the adoption of the Boltzmann statistics; a trapping site can trap unlimited number of deuterium atoms. Although the Fermi statistics $\left(z^{\prime} \geq 1\right)$ is more reasonable for the present problem, the simple treatment may give approximate values as far as the number of trapped deuterium atoms is smaller than that of trapping sites,

$$
N_{T}<z \text {. }
$$

In fact, this relation holds for the present case as is evident from Table 3 . The neglect of $z C_{o} / \beta$ does not introduce much difference in the value of $E_{B}$, if $z$ is around 10 .

$\dagger$ In this analysis we neglected the presence of small amounts of oxygen in V-D series specimens.
(2) $z^{\prime}=1$

The assumption of $z^{\prime}=1$ implies that an oxygen atom can trap $z$ deuterium atoms (no blocking). The best set of $E_{B}$ and $z$ may be found by minimizing the following quantity (i.e. the least squares method)

$$
\Delta=\sum\left[\frac{C_{D O}^{\mathrm{cal}}-C_{D O}^{\mathrm{exp}}}{C_{D O}^{\mathrm{exp}}}\right]^{2},
$$

to yield

$$
E_{B}=0.10 \mathrm{eV}, \quad z=14 .
$$

(3) $z^{\prime}=2$

With the assumption that a trapped deuterium blocks another trapping site $\left(z^{\prime}=2\right)$, $\Delta$ was also minimized:

$$
E_{B}=0.09 \mathrm{eV}, \quad z=21 .
$$

It must be noted here that Pfeiffer and Wipf $^{(15)}$ calculated the binding energy for $\mathrm{Nb}-\mathrm{H}-\mathrm{N}$ alloys with the assumption $z^{\prime}=z$ which means only one hydrogen atoms can be trapped per nitrogen atom. This is not appropriate for our case because the average number of trapped deuterium atoms to one oxygen atom, $N_{T}$, is always larger than 1 .

The values of the binding energy, $E_{B}$, evaluated on the three different assumptions are $0.09 \sim 0.10 \mathrm{eV}$. The number of the trapping sites per oxygen atom, $z$, is different for each calculation: $z=12 \sim 21$. Although we have assumed that all the trapping sites are equivalent and have an equal binding energy, the presence of different types of trapping sites should be assumed for a more detailed calculation. In other words, the value of $E_{B}$ estimated here should be understood as an averaged value over various sites with different binding energies.

The binding energy of the order of $0.1 \mathrm{eV}$ has also been found in $\mathrm{V}-\mathrm{H}-\mathrm{O}^{(2)}$ and $\mathrm{Nb}-\mathrm{H}-$ $\mathrm{O}^{(16)}$ alloys.

The solubility of deuterium in vanadium was also determined by Cannelli and Mazzolai with the internal friction technique ${ }^{(5)}$ as compared in Fig. 6: two results are considerably different. 
The origin of the discrepancy is not clear at present. The difference in impurity content may be a cause. It should be noted that they measured the internal friction at $\sim \mathrm{kHz}$, while we worked at a low frequency of about $1 \mathrm{~Hz}$. As will be discussed later, the mechanisms of the internal friction are not the same for the two frequency ranges, which might also be a possible origin of the discrepancy.

The magnitude of the thermal hysteresis, $\Delta T_{C H}$, is larger for oxygen bearing specimens as shown in Fig. 7. It is natural to ascribe the difference to a trapping effect of oxygen. However, the increase of $\Delta T_{C H}$ with the increase in deuterium concentration seems difficult to explain by a simple idea of the trapping effect.

\section{The nature of precipitation peak}

The precipitation peak in metal-hydrogen systems has been mainly studied at higher frequencies ( $\gg 1 \mathrm{~Hz}$ ), and dislocations generated around hydride precipitates have been considered to play a major role in the observed relaxation. However, this interpretation may not be directly applicable to the result of low frequency measurements.

As shown in this paper the precipitation peak consists of the transient and equilibrium components. The transient component, $Q_{T}^{-1}$, depends on both the heating rate, $\dot{T}$, and the frequency of the measurement, $f$, (see Figs. 9 and 11);

$$
Q_{T}^{-1} \propto \dot{T} / f .
$$

This type of the behaviour was found for the internal friction associated with the precipitation of hydrides in the Ti-H system by Köster, Bangert and Evers ${ }^{(17)}$. They attributed this peak to dissolution and precipitation of hydrides. The origin of the equilibrium component of the precipitation peak is not clear at present and further investigations are required.

From the results shown in Figs. 12 and 13, it is reasonable to consider that dislocations formed around deuterides by thermal cycling are responsible for a small peak at $-120^{\circ} \mathrm{C}$. It seems interesting to refer here to the work at high frequencies by Cannelli and Mazzolai on $\mathrm{Ta}-\mathrm{H}^{(7)}$ and by Cannelli and Cantelli on Ta- $\mathrm{D}^{(6)}$. They observed that the precipitation

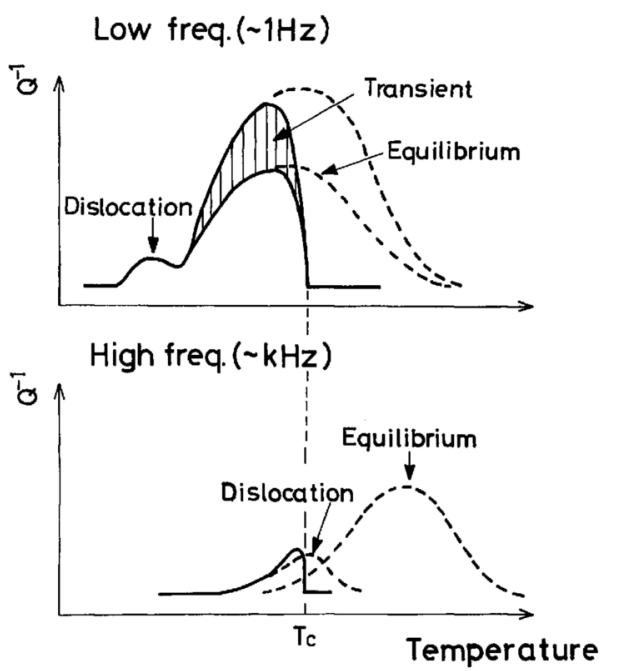

Fig. 14 The precipitation peak for low and high frequency measurements (schematic).

peak grows extensively by thermal cycling; the trends are very similar to our small peak at $-120^{\circ} \mathrm{C}$.

Thus, our understanding of the precipitation peak at low and high frequencies may be schematically expressed in Fig. 14. With the increase in the frequency, the transient component diminishes (see Fig. 11 or eq. (6)). The equilibrium component would shift to higher temperatures, if the process is the thermal activation type. At the same time, the dislocation relaxation observed at about $-120^{\circ} \mathrm{C}$ in the lower frequency measurement shifts towards higher temperatures. Therefore, with the increase in the frequency, the precipitation peak would become essentially of dislocation origin. The precipitation peak measured at higher frequencies $(\sim \mathrm{kHz})$ is due to dislocations formed around precipitates, while the precipitation peak measured at low frequencies $(\sim 1$ $\mathrm{Hz}$ ) should be ascribed to some relaxations directly associated with precipitates themselves.

\section{Conclusion}

The solubility limit of deuterium in vanadium is greatly affected by the addition of impurity oxygen. The oxygen atoms trap the deuterium atoms and the solubility is increased because of reduction of effective deuterium concentration in the $\alpha$-matrix of vanadium. The average 
binding energy of deuterium to oxygen is estimated to be about $0.10 \mathrm{eV}$.

The so-called precipitation peak observed in metal-hydrogen system has several components; namely transient, equilibrium and dislocation components. The transient component depends on the cooling or heating rate and the measuring frequency, and is related to the dissolution of hydride as proposed by Köster et al. ${ }^{(17)}$ The equilibrium component is probably due to precipitates themselves but the detailed mechanism remains to be clarified. The dislocation component is due to dislocations punched out from hydride precipitates. At lower frequencies $(\sim 1 \mathrm{~Hz})$, this component is observed as a separate peak at the lower temperature side of the main precipitation peak. At higher frequencies $(\sim \mathrm{kHz})$, the bulk of the precipitation peak is ascribed to dislocations.

\section{Acknowledgements}

The authors are grateful to Mr. K. Abe for the advice in $\mathrm{Zr}$-foil-wrapping-anneal technique, and to Dr. F. Abe for the help in the measurement of the residual resistivity ratio. They also wish to thank Messers S. Ono, $\mathrm{K}$. Wako and K. Obara for helps in the preparation of specimens.

This work is partly supported by Grant in Aid for scientific research from the Ministry of Education.

\section{REFERENCES}

(1) P. Schiller: Nuovo Cimento Soc. Ital., 33B (1976), 226.

(2) H. Y. Chang and C. A. Wert: Acta Met., 21 (1973), 1233.

(3) O. Buck, D. O. Thompson and C. A. Wert: J. Phys. Chem. Solids, 34 (1973), 591.

(4) H. Y. Chang and C. A. Wert: Ber. Bunsenges. Phys. Chem., 77 (1973), 42.

(5) G. Cannelli and F. M. Mazzolai: Appl. Phys., 1 (1973), 111.

(6) G. Cannelli and R. Cantelli: Internal Friction and Ultrasonic Attenuation in Crystalline Solids, Ed. by D. Lenz and K. Lücke, Springer-Verlag (1975), vol. 1, p. 250.

(7) G. Cannelli and F. M. Mazzolai: Nuovo Cimento Soc. Ital., 64B (1969), 171.

(8) G. Cannelli and F. M. Mazzolai: J. Phys. Chem. Solids, 31 (1970), 1913.

(9) F. Povolo and E. A. Bisogni: J. Nucl. Mater., 29 (1969), 82.

(10) V. Provenzano, P. Schiller and A. Schneiders: J. Nucl. Mater., 52 (1974), 75.

(11) K. Abe, K. Toma, H. Yoshinaga and $\mathbf{S}$. Morozumi: J. Less-Common Metals, 23 (1971), 213.

(12) G. Hörz: Z. Metallk., 61 (1970), 371.

(13) M. Koiwa and M. Hirabayashi: Sci. Rep. RITU, A-18 Suppl. (1966), 344.

(14) C. V. Owen and T. E. Scott: Met. Trans., 3 (1972), 1715.

(15) G. Pfeiffer and H. Wipf: J. Phys. F6 (1976), 167.

(16) C. Baker and H. K. Birnbaum: Acta Met., 21 (1973), 865.

(17) W. Köster, L. Bangert and M. Evers: Z. Metallk., 47 (1956), 564. 